\title{
En el paraíso soviético
}

DIEZ MINUTOS PARA CASARSE, NUEVE PARA DIVORCIARSE

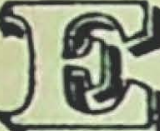

N la actual Rusia Soviética, para contraer matrimonio se necesitan dos; pero para divorciarse basta con uno. $\mathrm{Y}$ el divorcio se consigue con una rapidez inimaginable; diez minutos son tiempo suficiente para casarse; en diez minutos se hacen todas las tramitaciones y pueden llenarse todos los requisitos, pero el procedimiento de divorcio es más rápido aún, puesto que en nueve minutos queda listo.

Por regla general, es hoy tan fácil conseguir en Rusia el diorcio, como sacar una licencia para conducir un automóvil; tan facil es, que yo mismo quise experimentar personalmente esta verdad $y$ en nueve minutos estaban terminadas todas las formalidades del caso.

Acompañado de un intérprete, penetré en un edificio de ladrillo, de dos pisos, que se halla situado junto a un cuartel de policía, en Moscú. Una mano con el índice extendido señala el camino que ha de seguirse para llegar a las oficinas del Regisro: un amplio salón en el que no hay más muebles que un armario, tres mesas de pino, colocada cada una en un ángulo de la estancia, y detrás de cada mesa una silla y en la silla un escribiente o funcionario.

- ¿Es aquí donde debe tramitarse el divorcio?-pregunté a un joven que evidentemente estaba a cargo de una de las mesas-registros.

- Sí, señor; tome asiento-me contestó con amabilidad.

- Yo soy norteamericano-expliqué en seguida por intermedio de mi intérprete- ¿PPede usted divorciar a un extranjero?

- ¿Cómo no!-me contestó sonriente.

- ¿Cuánto tiempo se precisará para esto, señor?

- Diez minutos cuando más, el tiempo necesario para que conteste usted las preguntas del formulario y extenderle el certificado.... ¿Cómo es su nombre?

Y rápidamente comenzó a llenar con mis respuestas las preguntas del formulario ad-hoc. Cuando llevaba ya escritas las dos terceras partes del formulario, me dió una especie de remordimiento de conciencia. $\mathrm{Y}$ en el espacio de tres minutos, 
después de contestar a otra media docena de preguntas, me encontré con que ya estaba divorciado.

Una vez en París, hace de esto cinco o seis años, fuí citado ante el juez para declarar en un proceso de divorcio y me causó una impresión enorme ver la facilidad con que allí pociía conseguirse el divorcio y hasta me asaltó su poco de remordimiento por parecerme que había yo contribuído con mi declaración a que se realizara en poco tiempo un divorcio que a mi juicio pudo muy bien haber terminado con un arreglo. iAhora el procedimiento había sido mucho más expedito y yo no figuraba como testigo sino como autor!....

Me dirigí entonces al escribiente esbozando algo así como una especie de sonrisa $\mathrm{y}$, siempre por conducto de mi intérprete, le dije que agradecía su atención, pero que yo era un escritor norteamericano y que había acudido allí solamente con el objeto de comprobar personalmente la facilidad con que en Rusia podía divorciarse quien quisiera.

- Muy bien-me contestó el oficial-, quiere decir que entonces no estamparé en el documento el sello oficial para que no sea válido; es lo único que falta. Yo le había asignado a su esposa una renta mensual de sesenta rublos (treinta dólares) para el mantenimiento de su hijo-agregó con una amable sonrisa.

-Dígame usted-volví a preguntar-, ¿qué validez tendría este documento en el caso que yo quisiera hacerlo efectivo?

El funcionario se encogió de hombros y me dijo:

-En la Unión del Soviet la validez es completa. A nosotros nada nos importa que en su país le den o no validez.... Aquí tiene usted el documento, haga usted de él el uso que tenga por conveniente.

Una joven acababa de entrar en la oficina y tomaba asiento frente a una de las otras mesas. Iba pobremente vestida y llevaba un chal a la cabeza, pero a pesar de su mísero aspecto se veía que era una jov'en de belleza poco común. Expuso que quería divorciarse.

la mesa.

$* * *$

- Sí, una niña de tres años-contestó.

- ¿Ha hecho usted con su marido algún convenio para el sostenimiento de la niña? 
- Sí, aquí tengo el papel; el padre se compromete a pasarme una renta de veinte rublos mensuales hasta que la niña tenga dieciséis años y a darme a mí quince rublos más por espacio de seis meses.

- Pero usted puede conseguir una pensión mayor que esa para su hija, si lo desea. El Tribunal del Pueblo puede acordarle mayor pensión-exclamó el oficial que me había atendido a mí.

- Bien, pero nosotros henios convenido en eso-respondió la mujer tranquilamente.

- ¿Cuánto gana el padre?- insistió el que parecía dirigir este asunto de divorcio.

- Ciento diez rublos al mes.

- Bueno, pues ya sabe usted que puede sacar más si lo desea, acudiendo al Tribunal del Soviet. ¿No es así, compañera?preguntó dirigiéndose a la otra mesa ante la que estaba sentada otra mujer.

Era ésta una abogado que asistía dos veces a la semana a la oficina de divorcios para que pudiesen consultarle gratis los que quisiesen averiguar cualquier asunto que les conviniera, relacionado con la separación.

-Efectivamente, puede obtener más-convino la abogado.

Pero la mujer volvió a encogerse de hombros y nadie volvió a hacer el menor comentario.

El escribiente empezó a preguntar. Yo miré mi reloj. Eran exactamente las 11 y 32 minutos.

- ¿Qué nombre va usted a usar después de la separación?preguntó.

-El de mi marido. Aquí está la autorización suya.

Y la joven sacó de un bolsillo el papel firmado por el marido, en donde la autorizaba a seguir usando su nombre. Sin este requisito la mujer hubiera tenido que volver a usar su nombre de soltera.

- ¿Qué edad tiene usted?-siguió preguntando el escribiente.

- Veintitrés años.

— ¿Ha sido casada anteriormente?

-No.

- ¿Y su marido lo fué?

- Tampoco.

- ¿Dónde está el convenio formulado entre ustedes para el mantenimiento de la hija?

- Figura ahí en el papel que acabo de darle: veinte rublos para mi hija hasta que esta cumpla dieciséis años y quince rublos más para mí por espacio de seis meses. 
Se oyó el rasguear de la pluma en el papel para tomar nota de todos estos datos. Y en seguida prosiguió el interrogatorio.

- ¿De qué nacionalidad son usted y su esposo?

-Rusos.

- ¿Qué ocupación tiene él?

- Trabaja en una fábrica.

- ¿Dónde va a vivir usted?

- En la dirección indicada en ese papel.

- ¿Quiere permitirme su carnet de identidad?

La mujer sacó su carnet y lo presentó al escribiente. Este le abrió, tachó con la pluma la palabra "casada» y escribió encima «divorciada». En seguida el escribiente pidió a la mujer que firmara al pie de la hoja en que había escrito, en el libro del registro. Hecho esto, devolvió a la joven su cêdula de identidad y le indicó que la presentara ante el oficial de la mesa en que yo estaba. El oficial la cogió automáticamente, tomó un sello de goma con tinta roja, lo estampó en el carnet y firmó encima. La joven volvió a coger su carnet, dió media vuelta y salió de la sala, libre y divorciada, sin haber gastado un solo centavo.

Miré el reloj. Eran las once cuarenta y un minuto exactamente. La tramitación completa del divorcio había, pues, durado nueve minutos.

- No se puede dar mayor rapidez-exclamé dirigiéndome al funcionario que me había divorciado a mí-. En varios Estados de Norte América cuesta divorciarse algunos meses y grandes sumas de dinero, y a más de esto todo individuo que se quiere divorciar tiene que echar una serie de mentiras y acudir a la farsa y a la intriga. No salgo de mi asombro al ver la pasmosa facilidad y rapidez con que aquí proceden ustedes para conseguir en breves ninutos y sin la menor dificultad lo que a nosotros nos cuesta tantos sinsabores y dólares.

- Nosotros-me respondió el escribiente-hacemos todo lo posible por eliminar en las cuestiones del matrimonio y el divorcio toda hipocresía. Si los cónyuges que no tienen hijos no desean seguir viviendo juntos, cualquiera de ellos puede presentarse en esta oficina y conseguir su divorcio inmediatamente. Cuando hay hijos de por medio, se necesita un convenio escrito respecto al sostenimiento de ellos. El que desee el divorcio puede obtenerlo sin dilación y no hace falta para ello siquiera que se entere el cónyuge, hasta después que haya sido verificado el divorcio. Nosotros opinamos que la mujer puede en este terreno tener los mismos privilegios que el hombre. Y por eso también, concediéndole la misma capacidad para la vida económica, le exigimos las mismas responsabilidades res- 
pecto a su prole. Usted puede ver. Ya no tenemos en Rusia el problema de los hijos ilegítimos. Podrá haber madres divorciadas, pero todo niño tiene su padre y cuando la madre lo señala, es financieramente responsable de la alimentación de sus hijos. Podrá este niño no contar con un hogar paterno y materno, pero a lo menos no es a nuestros ojos un desventurado como lo son entre ustedes los hijos ilegítimos. Aquí con respecto a los hijos no reconocemos sexos para la responsabilidad de los padres. Aquí las mujeres tienen....

La llegada de una pareja de jóvenes interrumpió la charla del funcionario. Este me miró sonriendo maliciosamente y me dijo:

- Aquí tiene usted un matrimonio.

Sonreí yo también al ver la pareja que parecía cohibida, cortada. Al momento me dí cuenta de su situación. Algo así me había pasado a mí muchos años atrás, cuando fuí a celebrar mi matrimonio.

La joven de la mesa de enfrente invitó a la pareja a tomar asiento frente a su escritorio, abrió otro libro-el de los matrimonios - y empezó a preguntar. Volví a consultar mi reloj. Eran las 11,45 .

- ¿Qué nombre va usted a tomar?

-El de él-contestó la muchacha.

Podía haber seguido usando el suyo si así lo hubiera querido. - ¿Qué edad tienen ustedes?

La joven dijo que 21 años; el novio que 24.

- ¿Ha sido alguno de ustedes casado anteriormente? ¿Han tenido hijos?

Ella contestó que no; él dijo que había sido casado antes, pero que no había tenido familia.

Siguióse a continuación la misma serie de preguntas que le habían hecho a la joven que acababa de divorciarse, sólo que la pregunta final fué ésta:

- ¿Desean ustedes casarse en alguna iglesia?

Los dos enamorados se encogieron de hombros y se quedaron mirándose el uno al otro. ¿Qué significaba esto para ellos? Sin ceremonia religiosa podian perfectamente ser uno del otro; podían conseguir su ambicionada felicidad sin más trámites. El escribiente presentó el libro del registro a ambos y los dos firmaron sonrientes; y alegres. Luego ambos novios vinieron a la mesa del funcionario con quien yo había intervenido. Yo me levanté y saludé. El oficial me dijo:

-Usted puede servir de testigo.

Tomó en seguida sus carnets, los timbró con el sello rojo, los firmó y quedaron ambos casados, es decir, inscritos en el regis- 
tro como marido y mujer. Miré mi reloj. Eran las 11.55. Diez minutos habían demorado en casarse y, lo mismo que el divorcio, sin costar un solo centavo.

En estos rnomentos parece que se trata en Rusia de reformar la cuestión de la tramitación de los matrimonios y los divorcios. Se me ha dicho que hay ya preparada una nueva legislación al respecto. Por un lado parece que dicha tramitación costará de cincuenta centavos a dos pesos cincuenta-según la renta del solicitante de divorcio-y la misma tarifa regirá para los matrimonios. Los extranjeros deberán pagar el máximum. de la tarifa, esto es, $\$ 2,50$, y, así como de paso, mi amigo el oficial me a.seguró que él había por su parte divorciado ya a numerosos norteamericanos y ciudadanos de otras nacionalidades debiendo tener en cuenta que su oficina es sólo una de las seis que para el efecto funcionan en la ciudad de Moscú.

Los dos días siguientes a mi pseudo-divorcio los invertí en compulsar las estadísticas de divorcios y matrimonios. Durante el año de 1928 pude comprobar que sólo en Moscú se habían celebrado 28,175 matrimonios y 21,220 divorcios, es decir, un setenta y cinco de divorcios con relación a la cantidad de matrimonios.

De estos 21,220 divorcios, 279 habían sido de individuos casados dentro de la quincena; su matrimonio había durado por consiguiente, un máximum de quince dias; 323 se habían divorciado al mes de casarse; 1213 entre el primero y el tercer mes; 1243 entre el tercero y el sexto; 1492 entre los seis y los doce meses; 2095 entre el primero y segundo año; 1802 entre el segundo y el tercero; 3237 habían durado juntos de tres a cinco años; 5840 , de cinco a diez años; 1624 , de diez a quince; 1022 de quince a veinte y 1050 parejas habían permanecido unidas por espacio de más de veinte años.

En toda Rusia se habían verificado durante el citado año de 1928, según las estadísticas, 1.322 .392 matrimonios y 342.924 divorcios - poco menos del treinta por ciento-. En las ciudades y poblaciones de menos de 50.000 almas se produjeron 254.377 divorcios y 1.150,434 matrimonios, pero en las grandes ciudades como Petrogrado y Moscú hubo 88,547 divorcios por 171,958 matrimonios, o sea, más del cincuenta por ciento de los matrimonios se divorciaron en las grandes capitales de la Unión Soviética.

En cuanto a las edades, hubo 29 hombres y 252 mujeres divorciados a los 18 años; 443 hombres y 364 mujeres a los 21; 1076 hombres y 355 mujeres a los 29 años; 4367 hombres y 3746 mujeres divorciados entre la edad de 30 y 34 años; 315 hombres y 93 mujeres entre los 55 y los 59 años; y 25 hombres y 3 mujeres con más de 70 años de edad. Un hombre se casó y 
se divorció siete veces en el término de dos años, pero las autoridades se negaron a concederle la unión por octava vez.

Los divorcios por incompatibilidad de caracteres o por malos tratos vi que eran los más corrientes entre el elemento joven. Y compulsando las mismas estadísticas, pude enterarme de casos notables. Una mujer, indignada porque su marido no había llegado a casa a almorzar a las dos, corrió a la oficina del registro y pidió el divorcio; el marido llegó tranquilamente a casa a las dos y media, pero su mujer con muy buenas palabras le dijo que nada tenía ya que hacer allí porque había conseguido su divorcio. El marido le suplicó que recapacitase, le expuso los motivos que había tenido para no llegar antes, motivos perfectamente justos, y entonces la mujer, convencida y comprendiendo su precipitación, corrió a las oficinas del Registro y a las tres de la tarde ya estaba casada de nuevo con su mismo marido; de modo que en el intervalo de una hora la mujer había estado caşada, divorciada y vuelta a casar. No cabe mayor expedición.

Contaron al autor de este artículo otro caso no menos gracioso. Dos cónyuges se divorciaron a las tres de la tarde. El marido se fué en busca de otra mujer con la que ya tenía apalabrado su enlace, para proceder a su realización; pero resultó que la mujer aquella, casada, no había tenido tiempo aún de ir a las oficinas del Registro ni era ya hora de tramitar su divorcio hasta el otro día. El aspirante a marido tuvo, pues, que aplazar hasta el día siguiente su nuevo matrimonio y se volvió a la casa de su antigua mujer. $Y$ aquí viene la parte graciosa: la mujer, más lista que él, se había vuelto a casar aquella misma tarde y estaba en casa con su nuevo marido. Por condescendencia tuvo que alojar aquella noche en su antiguo hogar donde mandaba ya otro dueño, que celebraba aquella noche su luna de miel con su divorciada esposa.

Así se estilan las cosas en el paraíso bolchevique, la tierra de los grandes experimentos para la reorganización social. FRAZIER H UNT.

Traducción de $\mathbf{R}$. Mondría.

\section{Una lectura incitante}

(D) ICEN que Karl Joris Huysmans, inventor del decadentismo, deleitaba sus ocios leyendo catálogos de librería. Hay otro jardín de incitaciones aun más sugerente, complejo y amplio, porque en sus cuadros no se mueven sombras, como en los libros, sino creaturas vivas; y 